BMJ Open Sport \& Exercise Medicine

\section{Elite coaches have a similar prevalence of depressive symptoms to the general population and lower rates than elite athletes}

To cite: Kim SSY, Hamiliton B, Beable S, et al. Elite coaches have a similar prevalence of depressive symptoms to the general population and lower rates than elite athletes. $B M J$ Open Sport \& Exercise Medicine 2020;6:e000719. doi:10.1136/ bmjsem-2019-000719

- Additional material is published online only. To view please visit the journal online (http://dx.doi.org/10.1136/ bmjsem-2019-000719).

Accepted 15 March 2020
Check for updates

(C) Author(s) (or their employer(s)) 2020. Re-use permitted under CC BY-NC. No commercial re-use. See rights and permissions. Published by BMJ.

\section{${ }^{1}$ Axis Sports Medicine} Specialists, Auckland, New Zealand

${ }^{2}$ High Performance Sport New Zealand, Auckland, New Zealand ${ }^{3}$ School of Population Health, The University of Auckland-City Campus, Auckland, New Zealand ${ }^{4}$ New Zealand Football, Football House, QBE Stadium, Stadium Drive, Albany, Auckland, New Zealand

Correspondence to Dr Simon Sang Yeob Kim; s.kim@axissportsmedicine.co.nz

\section{ABSTRACT}

Objective The primary aim of this study was to estimate the prevalence of depressive symptoms and life stress in elite coaches. The secondary aim was to explore the associations of depressive symptoms and life stress with demographic and lifestyle variables.

Methods National-level coaches were invited to participate in an online survey. Depressive symptoms were measured by the Centre for Epidemiological Studies Depression Scale-Revised (CESD-R). Life stress was measured using daily life hassle frequency and severity scores calculated from the Daily Hassles Questionnaire, with associations evaluated using linear regression. Results of 110 potential participants, 69 completed and two partially completed surveys were received. The majority of respondents were male $(77 \%)$, coaching individual sports (70\%) and aged under 50 (71\%). Overall, $14 \%$ of coaches reported at least moderate depressive symptoms according to the CESD-R. Those contemplating retirement were more likely to show depressive symptoms. Reported life stress was higher in females and in those contemplating retirement. There was a strong association between life stress and the odds of experiencing depressive symptoms $(p=0.006)$.

Conclusions Depressive symptoms are as prevalent in elite coaches as in general population, with potential risk factors including high levels of life stress and impending retirement.

\section{INTRODUCTION}

Depressive symptoms and disorders are the most prevalent psychological problems worldwide. A recent meta-analysis illustrated the prevalence of symptoms of depression and anxiety in elite athletes to be as high as $34 \%{ }^{1}$ In New Zealand elite athletes were found to have a prevalence of $21 \%$ for depressive symptoms ${ }^{2}$ while $14 \%$ of the adult population has been diagnosed with depression in their lifetime. ${ }^{3}$ An international professional rugby study, which included New Zealand players, found the prevalence for depressive and anxiety symptoms to be $28 \% .^{4}$ Recognising

\section{What are the new findings}

- The prevalence of depressive symptoms in elite coaches in New Zealand is $14 \%$. This is lower compared with the elite athletes, but is comparable to the general population.

- High levels of life stress are associated with higher odds of depressive symptoms in elite coaches. There may also be an association of depressive symptoms with contemplation of retirement and family history of mood disorders, although further research is needed to confirm these associations.

- The most common types of life stress for the elite coaches include future thoughts, responsibilities and high standards.

How might it impact on clinical practice in the near future

The findings could help raise awareness about mental health problems in the elite coaching community and lead to enhanced mental health support.

this issue, the IOC recently published a consensus statement on mental health in elite athletes. ${ }^{5}$ While there is emerging evidence that other groups, such as elite-level referees, are affected by symptoms of mental health disorders, ${ }^{6}$ there remains little awareness of the mental health of elite coaches.

Coach roles in elite sport are challenging with multiple functions, expectations and visible outcomes, resulting in many rolespecific stressors. ${ }^{7}$ These include a range of personal and situational factors, contractual matters, a lack of job security, long working hours, unclear expectations, frequent travel and lack of social support. ${ }^{7-9}$ Existing research has focused on coaches' approaches to stress management, ${ }^{710}$ and their knowledge and attitudes towards depression among the athletes they coach. ${ }^{11}$ The prevalence of 
depressive symptoms in elite sport coaches has not been formally studied.

The primary aim of the current study was to evaluate the prevalence of depressive symptoms and life stressors experienced by New Zealand elite-level coaches. The secondary aim was to explore the potential association of depressive symptoms and life stress with demographic and lifestyle variables.

\section{METHODS}

A cross-sectional study was conducted among elite coaches working at either a national or international level with elite athletes, employed by either High Performance Sport New Zealand or New Zealand Football and aged 18 years or older. Potential participants received a link to an anonymous online survey (online supplementary appendix 1), which was hosted on a secure online platform. A total of 110 coaches were invited to participate.

The Centre for Epidemiological Studies Depression Scale-Revised was used to measure symptoms of depression. ${ }^{12}$ The 'Daily Hassles Scale' was used to measure life stress. ${ }^{13}$ Further details of the questionnaires are presented in the online supplementary section.

The prevalence of depressive symptoms was calculated along with exact binomial 95\% CIs. $\chi^{2}$ test or Fisher's exact test (for small cell counts) was used to evaluate associations of coach characteristics with the presence of either moderate or major depressive symptoms. Significant associations $(\mathrm{p}<0.05)$ were then assessed together in an adjusted logistic regression model, with results presented using ORs and 95\% CIs. Potential associations of life stress with coach characteristics were assessed using a Kruskal-Wallis test due to the non-normal distribution of the continuous daily life hassle frequency and severity scores. Significant associations from unadjusted analysis were then evaluated together in a multiple linear regression model. Normality of residuals was evaluated for linear regression models. The association of life stress and depressive symptoms was also considered in unadjusted and adjusted (for coach characteristics associated with depressive symptoms) logistic regression models.

\section{RESULTS}

Sixty-nine elite coaches fully completed the survey and two partially completed the survey, resulting in the response rate of $65 \%$. Coach 'characteristics' are presented in table 1 . The majority of respondents were male $(77 \%)$, with 15 female $(21 \%)$ and one gender diverse participants. To protect anonymity, the gender diverse individual was excluded from any analyses including gender.

The prevalence of depressive symptoms and life stress (number of daily hassles) is shown in table 2. Ten coaches met the criteria for at least moderate depressive symptoms, with a prevalence of $14.1 \%$ (95\% CI $7.0 \%$ to $24.4 \%$ ). The average number of hassles reported was 24 . There was a strong positive correlation between the total number of daily hassles and the average severity score being reported (Spearman's $r=0.63, p<0.001$ ). Figure 1 shows the top-ranked daily hassles reported by the participants.

Unadjusted analysis showed that contemplating retirement $(\mathrm{OR}=6.56,95 \%$ CI 1.27 to $42.73 ; \mathrm{p}=0.010)$ and having a family history of mood disorder $(\mathrm{OR}=4.08$, $95 \%$ CI 1.01 to $16.41 ; \mathrm{p}=0.037$ ) were associated with a depressive symptom score of $\geq 16$ (table 2). Using an adjusted logistic regression model including both variables, only the association with contemplation of retirement remained significant, where the odds of moderate or higher depressive symptom levels for those considering retirement were 5.71 times higher than those not considering retirement (95\% CI 1.27 to 25.63 , $\mathrm{p}=0.023)$. There were no significant associations between other demographic factors and depressive symptoms.

The total daily hassles and severity score according to coach characteristics are displayed in table 3. Female coaches reported an average of 14 more daily hassles $(\mathrm{p}=0.022)$, and perceived these stressors as being more severe $(p=0.027)$ when compared with male coaches. Coaches not planning to retire within the next 12 months reported less daily hassles $(p=0.015)$ and less severe hassles $(\mathrm{p}=0.011)$ compared with those who were either contemplating or planning to retire within 12 months. Including both these variables in an adjusted regression model, associations with the total daily hassles score remained statistically significant. There were no significant associations between other demographic factors and the number or severity of daily life hassles.

There was a strong association between the total number and severity of daily hassles and depressive symptoms $(p<0.001)$. These associations persisted after adjustment for retirement plans and family history of mood disorder, with an average of $7 \%$ increase in the odds of experiencing symptoms consistent with moderate or major depression for each additional daily hassle reported $(\mathrm{OR}=1.07,95 \% \mathrm{CI} 1.02$ to $1.12, \mathrm{p}=0.007)$.

\section{DISCUSSION}

To our knowledge, this is the first study exploring the prevalence of depressive symptoms and daily hassles in coaches of elite athletes. The $14 \%$ prevalence of clinically relevant depressive symptoms we observed in this coach population is comparable to the rates of clinically diagnosed anxiety and depression in the New Zealand adult population, ${ }^{3}$ but lower than reported symptom rates among elite athletes based in New Zealand $(21 \%)^{2}$ and Australia (20\%). ${ }^{14}$ There may be a number of explanations for this difference. Compared with elite-level athletes, coaches are generally older. Ninety per cent of the coaches in this sample were older than 30 years of age, compared with $17 \%$ of athletes. ${ }^{2}$ Older adults have been shown to have a higher 'sense of coherence' and 'self-esteem' and lower overall rates of depression and distress. ${ }^{15}$ The observed difference could relate to a coaching selection bias. Among elite coaches, traits such as perseverance, optimism, hope and resilience are desirable and have been recognised as being important for 
Table 1 Characteristics of 71 coaches participating in the survey, overall and by depressive symptoms

\begin{tabular}{|c|c|c|c|c|c|}
\hline \multirow[b]{2}{*}{ Characteristic } & \multirow[b]{2}{*}{ n (\% of total) } & \multicolumn{2}{|c|}{$\begin{array}{l}\text { Moderate or major depressive } \\
\text { symptoms reported (CESD-R } \\
\geq 16 \text { ) }\end{array}$} & \multirow[b]{2}{*}{$P$ value† } & \multirow[b]{2}{*}{$\begin{array}{l}\text { Adjusted } \\
\text { P value }\end{array}$} \\
\hline & & $\begin{array}{l}\text { No; } n=61 \\
\text { n (col \%) }\end{array}$ & $\begin{array}{l}\text { Yes; } n=10^{*} \\
\text { n (col \%) }\end{array}$ & & \\
\hline \multicolumn{6}{|l|}{ Age (years) } \\
\hline 20-39 & $27(38.0)$ & $23(37.7)$ & $4(40.0)$ & 0.999 & - \\
\hline $40-49$ & $24(33.8)$ & $21(34.4)$ & $3(30.0)$ & & \\
\hline $50+$ & $20(28.2)$ & $17(27.9)$ & $3(30.0)$ & & \\
\hline Female§ & $15(21.4)$ & $12(19.7)$ & $3(33.3)$ & 0.392 & - \\
\hline \multicolumn{6}{|l|}{ Sport type } \\
\hline Individual & $50(70.4)$ & $42(68.9)$ & $8(80.0)$ & 0.712 & - \\
\hline Team & $21(29.6)$ & $19(31.1)$ & $2(20.0)$ & & \\
\hline Played professionally/semiprofessionally & $44(62.0)$ & $36(59.0)$ & $8(80.0)$ & 0.205 & - \\
\hline Centralisation for sport & $27(38.0)$ & $24(39.3)$ & $3(30.0)$ & 0.732 & - \\
\hline \multicolumn{6}{|l|}{ In paid employment outside of coaching } \\
\hline Yes, full time & $17(23.9)$ & $14(23.0)$ & $3(30.0)$ & 0.680 & - \\
\hline Yes, part time & $7(9.9)$ & $6(9.8)$ & $1(10.0)$ & & \\
\hline Very occasionally & $9(12.7)$ & $7(11.5)$ & $2(20.0)$ & & \\
\hline Not at all & 38 (53.5) & $34(55.7)$ & $4(40.0)$ & & \\
\hline \multicolumn{6}{|l|}{ Considering retirement in next 12 months } \\
\hline No & $48(67.6)$ & $45(73.8)$ & $3(30.0)$ & 0.010 & 0.023 \\
\hline Yes or undecided & $23(32.4)$ & $16(26.2)$ & $7(70.0)$ & & \\
\hline \multicolumn{6}{|l|}{ General Health } \\
\hline Previous concussion from injury & $28(39.4)$ & $24(39.3)$ & $4(40.0)$ & 1.000 & - \\
\hline Injury ended playing career & $13(18.3)$ & $11(18.0)$ & $2(20.0)$ & 1.000 & - \\
\hline Ever diagnosed with depression & $7(9.9)$ & $6(9.8)$ & $1(10.0)$ & 1.000 & - \\
\hline Ever been prescribed antidepressants & $8(11.3)$ & $7(11.5)$ & $1(10.0)$ & 1.000 & - \\
\hline Family history of mood disorder or mental illness & $17(23.9)$ & $12(19.7)$ & $5(50.0)$ & 0.037 & 0.115 \\
\hline Concerns about alcohol intake & $9(12.7)$ & $8(13.1)$ & $1(10.0)$ & 1.000 & - \\
\hline
\end{tabular}

${ }^{*} \mathrm{n}=7$ with moderate $(C E S D-R \geq 16)$ and $\mathrm{n}=3$ with major $(C E S D-R \geq 22)$ depressive symptoms.

†Unadjusted $p$ values are from Fisher's exact test (for cell counts $<5$ ) or $\chi^{2}$ test.

$\ddagger$ Adjusted $p$ values are from a logistic regression including 'considering retirement in 12 months' and 'family history of mood disorder or mental health'.

$\S \mathrm{n}=1$ gender diverse participant was not included when testing or adjusting for gender.

CESD-R, Centre for Epidemiological Studies Depression Scale-Revised.

Table 2 Depressive symptoms and life stress in NZ coaches

\begin{tabular}{|c|c|c|c|c|}
\hline Scale & n (\%) & Median (Q1, Q3) & Min & Max \\
\hline Depressive symptoms; CESD-R score & 71 & $7.0(3.0,12.0)$ & 0 & 32 \\
\hline No depressive symptoms (CESD-R <16) & $61(85.9)$ & & & \\
\hline Moderate depression (CESD-R 16-22) & $7(9.9)$ & & & \\
\hline Major depression (CESD-R >22) & $3(4.2)$ & & & \\
\hline \multicolumn{5}{|l|}{ Life stress } \\
\hline Total daily hassles score & 69 & $24.0(13.0,40.0)$ & 0 & 97 \\
\hline Daily hassle average severity score & 68 & $1.1(1.0,1.39)$ & 1 & 2.19 \\
\hline
\end{tabular}

CESD-R, Centre for Epidemiological Studies Depression Scale-Revised; NZ, New Zealand. 


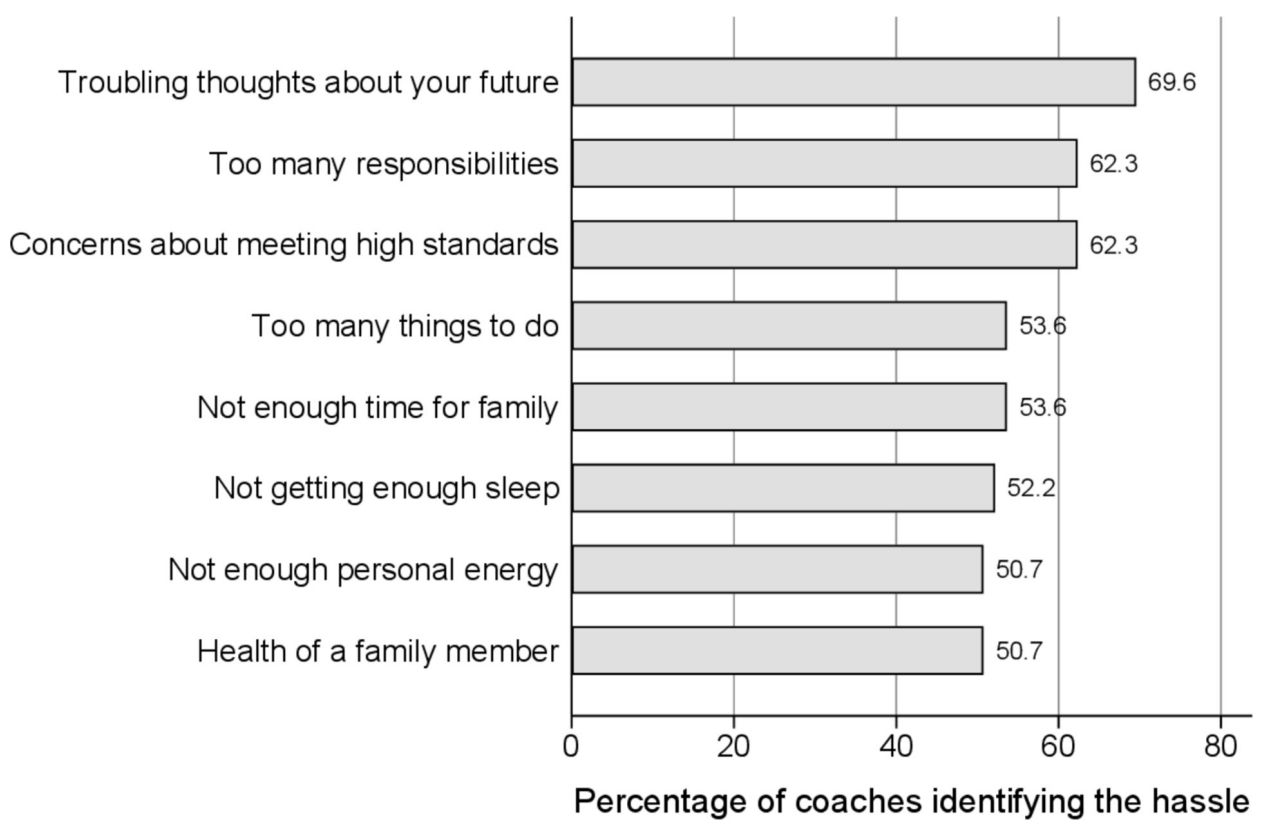

Figure 1 Daily hassles experienced by at least $50 \%$ of coaches in the study.

helping them cope with stress. ${ }^{16}$ These personality traits may be protective and individuals who do not have them may be less likely to become elite coaches. In contrast, success in elite athletes is related to the so-called 'big five trait dimensions'-openness, conscientiousness, extraversion, agreeableness and neuroticism. ${ }^{17}$ Finally, it is also possible that being an elite athlete is intrinsically more stressful than being an elite coach. This may be related to factors that are unique to elite sport where athletes generally have a short career, are always at risk of a career-ending injury and are directly responsible for their performance, ${ }^{18}$ when compared with coaches. Perhaps reflecting this, elite athletes report similar types of life stress, but more frequently, than coaches when given the same survey. ${ }^{2}$

As previously observed in elite athlete populations, ${ }^{2} 19$ we observed in coaches a positive association between clinically relevant depressive symptoms and retirement plans. The relatively small sample size is an important limitation of this study (largely due to the small number of elite-level coaches in New Zealand) and as a result statistical power and potential to perform subgroup analyses was limited. CIs for associations were wide for estimates comparing the odds of depressive symptoms and therefore the results from logistic regression in this study should therefore be interpreted cautiously.

High levels of daily hassles have been associated with moderate level of depressive symptoms in elite athletes, ${ }^{2} 19$ and a similar association was demonstrated in this coaching population. The understanding of the association between life stress levels and psychological disorders, especially in depression, is enlarging. ${ }^{20}$ It is, however, important to recognise that high level of life stress does not necessarily precede a depressive episode, with many other factors influencing. ${ }^{21}$ Improved understanding of these associations may allow those working within elite sport to identify the individuals at risk of experiencing depressive symptoms and help establish effective means of support.

Coaches provide a critical role, both in the athletes' quest for success, ${ }^{22}$ and in the early identification, intervention and guidance for athletes at risk of depression. ${ }^{1123}$ Chronically elevated stress levels can impact negatively on a coach's well-being, which may in turn reduce the individual's ability to best support athletes that they coach. $^{2425}$ Currently in New Zealand, there is no formal structure to support the mental health of most coaches of elite athletes. It is hoped that the data from this study will help direct strategies to better support this group. This may involve the provision of mental health education, monitoring well-being and the removal of barriers to seeking appropriate assistance. This research suggests that establishing support structures during periods of transition such as retirement and times of high life stress levels should be prioritised.

\section{CONCLUSION}

This is the first study to evaluate the prevalence of depressive symptoms in coaches of elite athletes. The current study has demonstrated that these coaches are affected by depressive symptoms, with a prevalence (14\%) comparable to the general New Zealand adult population but lower than the elite athlete population. Elite coaches are also affected by similar types of life stress to elite athletes, and there was a significant association between the reported number of daily life hassles and depressive symptoms. We hope that this study will help raise awareness about mental health problems in the elite coaching community and lead to enhanced mental health support. 
Table 3 Association of coach characteristics and life stress

\begin{tabular}{|c|c|c|c|c|c|c|}
\hline \multirow[b]{2}{*}{ Characteristic } & \multicolumn{3}{|c|}{ Daily hassle total score } & \multicolumn{3}{|c|}{ Daily hassle average severity score } \\
\hline & Median (Q1, Q3) & P value* & $\begin{array}{l}\text { Adjusted P } \\
\text { value† }\end{array}$ & Median (Q1, Q3) & P value* & $\begin{array}{l}\text { Adjusted } P \\
\text { valuet }\end{array}$ \\
\hline \multicolumn{7}{|l|}{ Age (years) } \\
\hline 20-39 & $28.5(18.0,41.0)$ & 0.614 & - & $1.2(1.0,1.4)$ & 0.828 & - \\
\hline $40-49$ & $25.0(11.0,37.0)$ & & & $1.1(1.0,1.4)$ & & \\
\hline $50+$ & $23.5(14.5,38.0)$ & & & $1.2(1.0,1.4)$ & & \\
\hline \multicolumn{7}{|l|}{ Gender } \\
\hline Male & $23.0(12.0,34.0)$ & 0.022 & 0.041 & $1.1(1.0,1.3)$ & 0.027 & 0.262 \\
\hline Female & $37.0(24.0,50.0)$ & & & $1.4(1.1,1.5)$ & & \\
\hline \multicolumn{7}{|l|}{ Sport type } \\
\hline Individual & $24.0(14.5,39.0)$ & 0.964 & - & $1.1(1.0,1.4)$ & 0.893 & - \\
\hline Team & $26.0(11.0,44.0)$ & & & $1.1(1.0,1.4)$ & & \\
\hline \multicolumn{7}{|l|}{ Played professionally } \\
\hline Yes & $28.0(14.0,44.0)$ & 0.128 & - & $1.2(1.0,1.4)$ & 0.517 & - \\
\hline No & $23.0(11.0,30.0)$ & & & $1.1(1.0,1.4)$ & & \\
\hline \multicolumn{7}{|c|}{ Centralisation for sport } \\
\hline Yes & $24.5(14.0,37.0)$ & 0.843 & - & $1.1(1.0,1.4)$ & 0.935 & - \\
\hline No & $24.0(11.0,41.0)$ & & & $1.1(1.0,1.4)$ & & \\
\hline \multicolumn{7}{|l|}{ Paid employment } \\
\hline Yes, full time & $21.0(12.0,29.0)$ & 0.287 & - & $1.0(1.0,1.1)$ & 0.210 & - \\
\hline Yes, part time & $32.0(15.0,58.0)$ & & & $1.2(1.1,1.4)$ & & \\
\hline Very occasionally & $37.0(26.0,51.0)$ & & & $1.2(1.1,1.4)$ & & \\
\hline Not at all & $24.0(12.0,40.0)$ & & & $1.2(1.0,1.4)$ & & \\
\hline \multicolumn{7}{|c|}{ Considering retirement } \\
\hline No & $23.0(11.0,36.0)$ & 0.015 & 0.035 & $1.1(1.0,1.2)$ & 0.011 & 0.090 \\
\hline Yes or undecided & $36.0(23.0,57.0)$ & & & $1.3(1.1,1.4)$ & & \\
\hline \multicolumn{7}{|c|}{ Previous concussion from injury } \\
\hline Yes & $30.0(12.0,50.0)$ & 0.302 & - & $1.2(1.0,1.4)$ & 0.174 & - \\
\hline No & $24.0(14.0,37.0)$ & & & $1.1(1.0,1.3)$ & & \\
\hline \multicolumn{7}{|c|}{ Injury ended playing career } \\
\hline Yes & $28.0(18.0,35.5)$ & 0.987 & - & $1.2(1.0,1.2)$ & 0.987 & - \\
\hline No & $24.0(12.0,40.0)$ & & & $1.1(1.0,1.4)$ & & \\
\hline \multicolumn{7}{|c|}{ Ever diagnosed with depression } \\
\hline Yes & $28.0(23.0,38.0)$ & 0.387 & - & $1.1(1.0,1.3)$ & 0.762 & - \\
\hline No & $24.0(12.0,40.0)$ & & & $1.1(1.0,1.4)$ & & \\
\hline \multicolumn{7}{|c|}{ Ever prescribed antidepressants } \\
\hline Yes & $26.5(19.5,47.5)$ & 0.378 & - & $1.1(1.0,1.4)$ & 0.856 & - \\
\hline No & $24.0(12.0,40.0)$ & & & $1.1(1.0,1.4)$ & & \\
\hline \multicolumn{7}{|c|}{$\begin{array}{l}\text { Family history of mood disorder or mental } \\
\text { illness }\end{array}$} \\
\hline Yes & $37.0(23.0,57.0)$ & 0.124 & - & $1.2(1.0,1.4)$ & 0.766 & - \\
\hline No & $24.0(12.5,36.5)$ & & & $1.1(1.0,1.4)$ & & \\
\hline \multicolumn{7}{|c|}{ Concerns about alcohol intake } \\
\hline Yes & $28.0(12.0,40.0)$ & 0.695 & - & $1.1(1.0,1.4)$ & 0.638 & - \\
\hline No & $24.0(13.5,39.0)$ & & & $1.2(1.0,1.4)$ & & \\
\hline
\end{tabular}

*Unadjusted $p$ values are from a Kruskal-Wallis test.

†Adjusted $p$ values are from a linear regression including 'considering retirement in 12 months' and gender. 
Acknowledgements We thank the High Performance Sport New Zealand (HPSNZ) and New Zealand Football for their assistance with this research. Financial assistance was provided by HPSNZ for statistical analysis.

Funding The authors have not declared a specific grant for this research from any funding agency in the public, commercial or not-for-profit sectors.

Competing interests None declared.

Patient consent for publication Not required.

Ethics approval Ethical approval was granted by the University of Auckland Human Ethics Committee (reference 020439).

Provenance and peer review Not commissioned; externally peer reviewed.

Data availability statement All data relevant to the study are included in the article.

Open access This is an open access article distributed in accordance with the Creative Commons Attribution Non Commercial (CC BY-NC 4.0) license, which permits others to distribute, remix, adapt, build upon this work non-commercially, and license their derivative works on different terms, provided the original work is properly cited, appropriate credit is given, any changes made indicated, and the use is non-commercial. See: http://creativecommons.org/licenses/by-nc/4.0/.

ORCID iD

Simon Sang Yeob Kim http://orcid.org/0000-0003-1194-2602

\section{REFERENCES}

1 Gouttebarge V, Castaldelli-Maia JM, Gorczynski P, et al. Occurrence of mental health symptoms and disorders in current and former elite athletes: a systematic review and meta-analysis. Br J Sports Med 2019;53:700-6.

2 Beable S, Fulcher M, Lee AC, et al. SHARPSports mental health awareness research project: prevalence and risk factors of depressive symptoms and life stress in elite athletes. J Sci Med Sport 2017;20:1047-52.

3 Ministry of Health. Mental health Foundation: quick facts and STATs 2014. 2014;:1-10. Available: https://www.mentalhealth.org. nz/assets/Uploads/MHF-Quick-facts-and-stats-FINAL-2016.pdf [Accessed 3 Nov 2019].

4 Gouttebarge V, Hopley P, Kerkhoffs G, et al. A 12-month prospective cohort study of symptoms of common mental disorders among professional rugby players. Eur J Sport Sci 2018;18:1004-12.

5 Reardon CL, Hainline B, Aron CM, et al. Mental health in elite athletes: international Olympic Committee consensus statement (2019). Br J Sports Med 2019;53:667-99.

6 Gouttebarge V, Johnson U, Rochcongar P, et al. Symptoms of common mental disorders among professional football Referees: a one-season prospective study across Europe. Phys Sportsmed 2017;45:11-16.
7 Norris LA, Didymus FF, Kaiseler M. Stressors, coping, and well-being among sports coaches: a systematic review. Psychol Sport Exerc 2017;33:93-112.

8 Knight CJ, Reade IL, Selzler A-M, et al. Personal and situational factors influencing coaches' perceptions of stress. J Sports Sci 2013;31:1054-63.

9 Rhind D, Scott M, Fletcher D. Organizational stress in professional soccer coaches. Int J Sport Psychol 2013;44:1-16.

10 Olusoga P, Butt J, Maynard I, et al. Stress and coping: a study of world class coaches. J Appl Sport Psychol 2010;22:274-93.

11 Hegarty EM, Weight E, Register-Mihalik JK. Who is coaching the coach? Knowledge of depression and attitudes toward continuing education in coaches. BMJ Open Sport Exerc Med 2018;4:e000339-7.

12 Van Dam NT, Earleywine M. Validation of the Center for Epidemiologic Studies Depression Scale--Revised (CESD-R): pragmatic depression assessment in the general population. Psychiatry Res 2011;186:128-32.

13 Holm JE. The Daily Hassles Scale (Revised): Does it measure stress or symptoms ? The Daily Hassles Scale (Revised): Does it Measure Stress or Symptoms ? Behav Assess 1992;14:465-82.

14 Gulliver A, Griffiths KM, Mackinnon A, et al. The mental health of Australian elite athletes. J Sci Med Sport 2015;18:255-61.

15 Stephens T, Dulberg C, Joubert N. Mental health of the Canadian population: a comprehensive analysis. Chronic Dis Can 1999;20:118-26.

16 Laborde S, Guillén F, Watson M, et al. The light quartet: positive personality traits and approaches to coping in sport coaches. Psychol Sport Exerc 2017;32:67-73.

17 Allen MS, Greenlees I, Jones M. An investigation of the five-factor model of personality and coping behaviour in sport. J Sports Sci 2011;29:841-50.

18 Wolanin A, Gross M, Hong E. Depression in athletes. Curr Sports Med Rep 2015;14:56-60.

19 Nixdorf I, Frank R, Hautzinger M, et al. Prevalence of depressive symptoms and correlating variables among German elite athletes. J Clin Sport Psychol 2013;7:313-26.

20 Hammen C, Kim EY, Eberhart NK, et al. Chronic and acute stress and the prediction of major depression in women. Depress Anxiety 2009;26:718-23.

21 Monroe SM, Reid MW. Life stress and major depression. Curr Dir Psychol Sci 2009;18:68-72.

22 Jowett S, Cockerill IM. Olympic medallists' perspective of the althlete-coach relationship. Psychol Sport Exerc 2003;4:313-31.

23 Van Slingerland KJ, Durand-Bush N, Bradley L, et al. Canadian centre for mental health and sport (CCMHS) position statement. Clin J Sport Med 2019;29:173-80.

24 Fletcher D, Scott M. Psychological stress in sports coaches: a review of concepts, research, and practice. J Sports Sci 2010;28:127-37.

25 Kallus KW, Kellmann M. Burnout in athletes and coaches. Emot Sport 2000:209-30. 